\title{
DALGACIK PAKET DÖNÜŞÜMÜ VE GENETİK ALGORİTMA KULLANARAK ZAYIF RADAR SİNYALLERİNİN GÜRÜLTÜDEN ARINDIRILMASI
}

\author{
Mehmet ÜSTÜNDAĞ $\breve{G}^{*}$,Engin AVCI**, Muammer GÖKBULUT ${ }^{* * *}$, Fikret ATA $^{* * * *}$ \\ *Fırat Üniversitesi, Teknik Eğitim Fakültesi, Elektronik ve Bilgisayar Eğitimi Bölümü, Elazı̆̆ \\ **Frrat Üniversitesi, Teknoloji Fakültesi, Yazılım Mühendisliği Bölümü, Elazı̆̆ \\ ***Frrat Üniversitesi, Teknoloji Fakültesi, Elektrik ve Elektronik Mühendisliği Bölümü, Elazığ \\ ****Frrat Üniversitesi, Mühendislik Fakültesi, Elektrik-Elektronik Mühendisliği Bölümü, Elazı̆ \\ mustundag@firat.edu.tr, eavci@firat.edu.tr, mgokbulut@firat.edu.tr, fata@firat.edu.tr
}

(Geliş/Received: 11.12.2012; Kabul/Accepted: 10.04.2014)

\begin{abstract}
ÖZET
Radar, haberleşme sistemlerinin önemli uygulama alanlarından birini oluşturur. Radar sinyali kaynaktan hedefe varıncaya kadar çevresel ya da insan kaynaklı nedenlerden dolayı asıl sinyale gürültü karışmış olabilir. Böylece, sinyalin doğru okunması imkânsız olabilir. Bu makalede, zayıf radar sinyallerini yüksek başarım ile gürültüden arındırmak amaçlanmıştır. $\mathrm{Bu}$ amaç doğrultusunda, geleneksel yöntemlerden farklı olarak Dalgacık Paket Dönüşümü kullanılmıştır. Bu dönüşümler gerçekleştirilirken, uygun dalgacık ailesi türü, entropi türü ve seviye seçimi oldukça önemli olmaktadır. Ayrıca, uygun bir eşik fonksiyonunun seçilmesi de yüksek başarım için önemlidir. Bu makalede, akıllı sistem olan Genetik Algoritma yapısı optimizasyon amaçlı önerilmiştir. Bu yapı ile birlikte, en iyi dalgacık ailesi türü, entropi türü ve seviye sayısı belirlenebilir. Eşikleme fonksiyonu olarak Bulanık s-fonksiyonu tercih edilmiş ve bu fonksiyona ait değişken parametreler en iyi başarım kriterine göre seçilmiştir. Daha sonra, zayıf radar sinyallerini gürültüden arındırabilmek için önerilen bu yöntem, literatürde mevcut olan diğer algoritmalarla karşılaştırılmıştır. Ortalama Karesel Hatanın Karekökü ve Korelasyon Katsayısı kriterleri kullanılarak başarımlar test edilmiştir. Elde edilen sonuçlara göre, önerilen yöntemin başarımının diğer yöntemlere göre oldukça iyi olduğu görülmektedir.
\end{abstract}

Anahtar kelimeler: Zayıf Radar Sinyali, Gürültüden Arındırma, Genetik Algoritma, Dalgacık Dönüşümü, Eşikleme, Ortalama Karesel Hatanın Karekökü, Korelasyon Katsayısı

\section{DENOISING OF WEAK RADAR SIGNALS USING WAVELET PACKET TRANSFORM AND GENETIC ALGORITHM}

\begin{abstract}
Radar constitutes one of the major application areas of communication systems. Until radar signal reaches from source to target, the noise may be mixed with the original signal because of environmental or human-induced reasons. Thus, it may be impossible to read the signal correctly. In this article, the purpose is to denoise the weak radar signals from noise with high-performance. For this purpose, Wavelet Packet Transform is used as different from the traditional methods. While these transforms are being performed, the selections of the appropriate wavelet family type, entropy type and level are quite important. Moreover, the suitable threshold function selection is important for high performance. In this article, the Genetic Algorithm structure as intelligent system for the optimization is proposed. With this structure, the best wavelet family type, entropy type and level number can be determined. Fuzzy s-function as thresholding function is preferred and variable parameters of this function are selected according to the best performance criteria. Then, this method, which is proposed for denoising the weak radar signals from noise, is compared with other algorithms available in the literature. The achievements are tested by using root mean square error and the correlation coefficient criteria. According to the obtained results, the achievement of proposed method is better than achievements of other methods.
\end{abstract}

Keywords: Weak Radar Signal, Denoising, Genetic Algorithms, Wavelet Transform, Thresholding, Root Mean Square Error, Correlation Coefficient 


\section{GIRISŞ (INTRODUCTION)}

Sinyal işleme alanında sıkça kullanılan zayıf sinyal terimi, Sinyalin Gürültüye Oranının (SGO) -10 dB'den daha az olduğu durum olarak açıklanabilir [1]. $\mathrm{SGO}$, giriş sinyalinin arka plan gürültüye olan nispi kuvvetini gösteren bir performans ölçütüdür $[2,3]$. Güçlü bir şekilde elektromanyetik gürültüye maruz kalındığı durumlarda gürültüden arındırma yöntemleri oldukça önem kazanmaktadır [4]. Geleneksel yöntemler sinyalin çok zayıf kaldığı durumlarda etkisini yitirmektedir [5]

Elektronik ve sinyal işlemenin ana uygulama alanlarından birini radar oluşturur [6]. Bir mikrodalga sistemi olan radar, mesafe tespiti ve nesneleri bulmak için kullanılır [7,8]. Alıcı sinyalin gücü, radarın hedefe uzaklığına ve hedef kesitine bağlıdır ve sinyale gürültü karışmışsa asıl sinyalin tespit edilmesi imkansız olabilir [9].

Zayıf sinyal tespiti ve gürültü giderimi ile ilgili literatürde birçok yöntem önerilmiştir. $\mathrm{Bu}$ yöntemlerin büyük çoğunluğunda, geleneksel sinyal işleme teknikleri olan Fourier Dönüşümü ve Güç Spektral Yoğunluğu gibi metotlar kullanılsa da, SGO oranının düşük kaldığı durumlarda bu yöntemler etkisini yitirmektedir $[5,10,11]$. Bununla birlikte son yıllarda, Dalgacık Dönüşümü tabanlı birçok yöntem önerilmiştir. [6]'da zayıf radar sinyallerinde gürültüyü giderebilmek için iki farklı yöntem önerilmiştir. Bunlar, Dalgacık Dönüşümünün bir Eşlenik filtre olarak kullanılmasına dayalı ve diğeri de farklı ölçeklerde elde edilen dalgacık katsayılarına dayalı bir yöntemdir. [9]'da Dalgacık Paket ve Yüksek Dereceli İstatistik kullanan bir yöntem önerilmiştir. [12]'de RBF Sinir Ağı tabanlı, Gauss olmayan gürültülü ortamlarda radar sinyallerini tespit edebilen bir algoritma sunulmuştur. [13]'de Dalgacık kullanan gürültüden arındırma algoritması, jeofizik verilerine uygulanmıştır. [14]'de ise Temel Bileşen Analizi yöntemi kullanan bir Dalgacık dönüşümü ile gürülttü arındırma yöntemi önerilmiştir. [15]'de Dalgacığa ait alt bantlarda Yüksek Dereceli İstatistik kullanan bir algoritma önermişlerdir. Gürülttülü biyomedikal sinyaller için Bulanık kural tabanında Dalgacık Dönüşümü kullanan bir algoritma [16]'da önerilmiştir. [17]'de gürültülü biyomedikal sinyaller için Dalgacık Dönüşümü tabanında Sure eşikleme kullanan gürültü giderimi algoritması önerilmiştir. [18]'de Yapay Sinir Ağı ve Dalgacık Dönüşümü ile ses sinyallerinin iyileştirilmesine ait bir algoritma önerilmiştir. Chui-Lian dalgacık kullanan yumuşak eşiklemeli gürültü giderim algoritması [19]'da önerilmiştir. [20]'de gürültü giderimi için Durağan Dalgacık Dönüşümü yöntemi, sert eşik ve yumuşak eşik kullanmak yerine yarı yumuşak eşikleme yöntemi ile yapılmıştır. Bulanık Eşikleme tabanlı Dalgacık Dönüşümü kullanan darbe sinyallerinin gürültüden arındırılması ile ilgili algoritma [21]'de önerilmiştir. [22]'de Dalgacık Analizi için Seviye Bağımlı Eşikleme kullanan Gamma ışın sinyallerinin gürültüden arındırılması algoritması önerilmiştir. [23]'de sinyalleri gürültüden arındırabilmek için Dalgacık Tabanlı Yayınım yaklaşımı önerilmiş ve başarımı geleneksel yöntemler ile karşılaştırılmıştır. Tek değerli ayrışım ve Dalgacık Paket kullanılarak dizel titreşimli sinyallerin gürültüden arındırılması için [24]'deki algoritma önerilmiştir. Biyomedikal sinyallerin gürültüden arındırılabilmesi için Dalgacık Dönüşümü Eşikleme kullanan algoritma [25]'de önerilmiş ve Donoho'nun yöntemi ile karşılaştırılmıştır. Yüksek Dereceli İstatistik ve Dalgacık Paket Dönüşümü kullanarak, sinyallerin gürültüden arındırılması için [26]'daki algoritma önerilmiş ve sinyallerin Yüksek Dereceli İstatistik özellikleri ve Dalgacık Dönüşümü birleştirilerek geçici ses sinyallerinin gürültüden arındırılması hedeflenmiştir. [27]'de konuşma sinyallerinin gürültüden arındırılması için Dalgacık Dönüşümünde eşikleme seçimi Yapay Sinir Ağları kullanılarak yapılmıştır. Komşu katsayılarını kullanan çoklu Dalgacık yapısı ile sinyallerin gürültüden arındırılması için dalgacık katsayılarında komşu olanlar birleştirilerek çoklu Dalgacık eşikleme yapısı [28]'de verilmiş̧tir.

Bu makalede, Dalgacık Paket Dönüşümü ile birlikte eşikleme fonksiyonu olarak Bulanık s-fonksiyon önerilmiştir. Dalgacık Dönüşümünde en iyi dalgacık ailesi türü, entropi türü ve seviye seçimi için Genetik Algoritma ile optimizasyon işlemi yapılmıştır. Önerilen ve karşılaştırılan yöntemlerin başarımını test edebilmek için istatiksel yöntemler olan Ortalama Karesel Hatanın Karekökü ve Korelasyon Katsayısı kriterleri kullanılmıştır.

\section{DALGACIK DÖNÜŞÜMÜ ve DALGACIK PAKET DÖNÜŞÜMÜ (WAVELET TRANSFORM and WAVELET PACKET TRANSFORM)}

Durağan olmayan sinyallerin analizinde Dalgacık Dönüşümü (DD) kullanılır. DD'de, sinyal boyunca kaydırılabilen ölçeklenebilir pencereler kullanılır ve her yeni konum için spektral davranışı incelenebilir. Fourier Dönüşümü'nde eşit pencere aralıklarında işlem yapılır. DD'de ise düşük frekanslarda büyük zaman aralığında işlemler yapılırken yüksek frekanslarda ise küçük zaman diliminde işlemler yapılmaktadır. Şekil 1'de zaman-frekans gösterimi verilmiştir [29,32]. Sürekli Dalgacık Dönüşümü (SDD), bütün zaman aralığı boyunca dalgacık fonksiyonunun sinyal ile çarpımı olarak tanımlanabilir. 


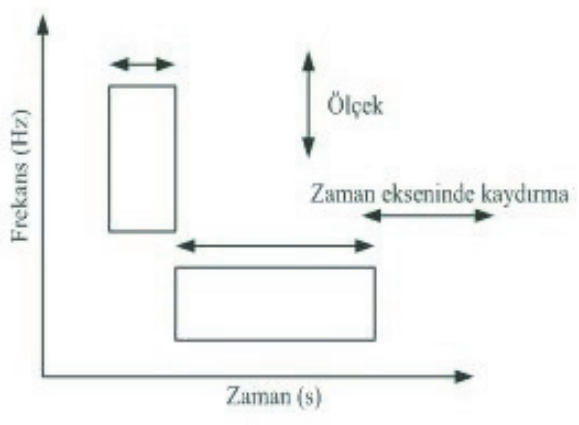

Şekil 1. Zaman-frekans gösterimi (Time-frequency representation)

SDD Denklem (1)'de zamana bağlı olarak gösterilmiştir [30].

$S D D(a, b)=\int_{-\infty}^{+\infty} f(t) \bar{\psi}_{(a, b)}(t) d t$

$\bar{\psi} \quad$ : Dalgacık fonksiyonunun karmaşık eşleniği

a : Ölçek parametresi

$b \quad$ : Kaydırma parametresi

$f(t)$ : Dönüşümü yapılacak fonksiyon

$\psi_{(a, b)}(t)$ : Dalgacık fonksiyonu

Ölçek ve kaydırma parametrelerinin kullanılmasıyla elde edilen dalgacık fonksiyonları Denklem (2)' de verilmiştir.

$$
\psi_{a, b}(t)=\frac{1}{\sqrt{a}} \psi\left(\frac{t-b}{a}\right)
$$

Denklem (2)'de elde edilen ifade SDD'nü hesaplayan Denklem (3)'de yerine yazılırsa;

$$
\operatorname{SDD}(a, b)=\frac{1}{\sqrt{a}} \int_{-\infty}^{\infty} f(t) \bar{\psi}\left(\frac{t-b}{a}\right) d t
$$

Kaydırma parametresi olan $b$, zaman-frekans gösterimindeki pencerenin geçici konumunu ifade eder. Sinyal üzerinde bu pencere kaydırıldığında frekans spektrumunun geçici bilgisi elde edilir. Ölçek parametresi olan $a$ 'nın, sinyalin frekansı $(f)$ ile ilgili bağıntısı Denklem (4)'de verilmiştir.

$a=\frac{1}{f}$

Ölçekleme, bir dalgacığın sıkıştırılması ya da genişletilmesidir küçük ölçek faktörüne sahip bir dalgacık sıkıştırılmış dalgacık anlamındadır [29,32].

\subsection{Dalgacık Paket Dönüşümü (Wavelet Packet Transform)}

Dalgacık Paket Dönüşümü (DPD), DD'den daha geniş bir sinyal işleme imkanı sağlar. DPD analizinin DD'den farkı detay bileşenlerinin de ayrışmasıdır. Bu sayede DPD dönüşümünde daha ayrıntılı bir şekilde frekans bileşenleri elde edilebilir. Eğer işlenecek sinyalin yüksek frekans bileşenlerinde önemli bilgiler saklanıyorsa bu dönüşüm yöntemini kullanmak daha uygun olacaktır. DPD'de, ayrıştırılma sonucunda elde edilen paketler toplam enerji korunma ilkesi gereğince tekrar birleştirildiğinde sinyal elde edilebilir $[31,32]$.

\section{RADAR DENEY SETINDEN VERILERIN ALINMASI (DATA OBTAINED FROM THE RADAR EXPERIMENTAL SYSTEM)}

Veriler alınırken Fırat Üniversitesi Teknik Eğitim Fakültesi Elektronik Bilgisayar Eğitimi bölümünde bulunan radar deney seti kullanılmıştır ve bu radar deney setine ait resim Şekil 2'de verilmiştir. Deney setinden alınan Radar Hedef Eko (RHE) sinyalleri MATLAB ortamında 750 örnek için ve $\mathrm{SGO}=0 \mathrm{~dB}$ olacak şekilde $48 \mathrm{kHz}$ 'lik örnekleme frekansıyla ses kartı kullanılarak bilgisayara aktarılmıştır [32,33]. Darbeli radar sinyalinin parametreleri; Pulse genişliği: 2 ns, RF osilatör frekansı: 9,4 GHz, Pulse tekrarlama frekansı: $144 \mathrm{~Hz}$ olarak ayarlanmıştır. Bu çalışmada kullanılan iki farklı hedef Şekil 3'de verilmiştir.

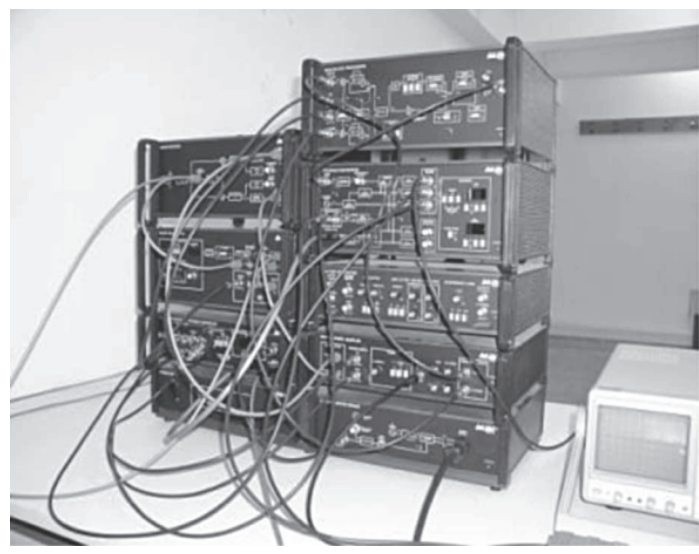

Şekil 2. Radar deney seti görünümü (View of the radar experimental system)

Tablo 1'de sırasıyla radar deney setinden alınan RHE sinyallerinin hedeflere göre dağılımı verilmiştir [33]. $\mathrm{Bu}$ hedeflere ait RHE sinyalleri Şekil 4 ve 5'de verilmiştir.

Tablo 1. RHE sinyallerinin hedeflere göre dağılımı (Distribution of the RHE signals according to the targets)

\begin{tabular}{llll}
\hline Hedefler & $\mathbf{9 0} \mathbf{c m}$ & $\mathbf{1 3 5} \mathbf{c m}$ & $\mathbf{1 8 0} \mathbf{~ c m}$ \\
Metal Plaka & 1 Adet & 1 Adet & 1 Adet \\
Küre & 1 Adet & 1 Adet & 1 Adet \\
\hline
\end{tabular}




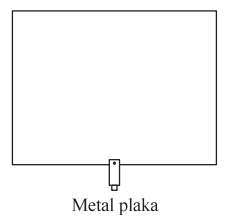

(a)

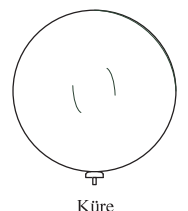

(b)
Şekil 3. (a) Metal plaka, (b) Küre ((a) Metal plaque, (b) Sphere)

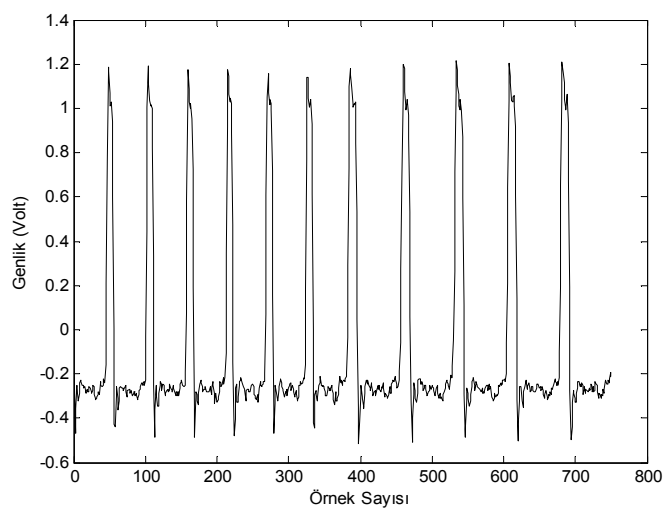

Şekil 4. $90 \mathrm{~cm}$ mesafede bulunan metal plaka hedefi için RHE sinyali

(The RHE signal for the metal plate from the distance of $90 \mathrm{~cm}$ )

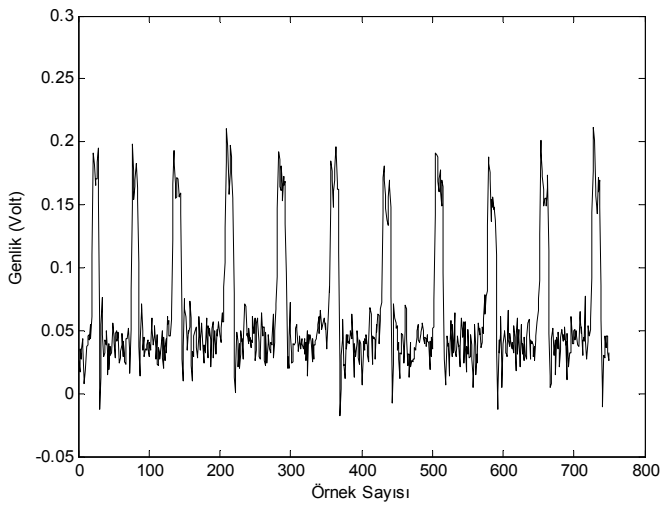

Şekil 5. $90 \mathrm{~cm}$ mesafede bulunan küre hedefi için RHE sinyali

(The RHE signal for the sphere from the distance of $90 \mathrm{~cm}$ )

\section{DALGACIK DÖNÜŞÜMÜ İLE GÜRÜLTÜDEN ARINDIRMA (DENOISING WITH WAVELET TRANSFORM)}

Gürültülü sinyalden asıl sinyali elde etmek için kullanılan yöntemler, gürültüden arındırma algoritmaları olarak bilinir. Denklem (5)'de gürültü ilave edilmiş sinyale ait ifade verilmektedir.

$y[n]=x[n]+d[n]$

Burada $x$ orijinal sinyali, $d$ eklenen gürültüyü, $y$ ise gürültülü sinyali göstermektedir. Orijinal sinyalin düşük frekansa sahip olduğu kabul edilmesine rağmen yüksek frekanslı bileşenleri de içerebilir. [34]. DD sayesinde orijinal sinyale ait yüksek frekanslı bileşenler korunur. Bundan dolayı gürültülü sinyallerden orijinal sinyalleri elde etmede DD önemli rol oynar. Geleneksel Dalgacık Eşikleme yöntemlerinde, DD'den elde edilen katsayılar yumuşak ya da sert eşiklemeden geçirilerek filtreleme yapılır. Bu eşikleme yöntemlerine ait ifadeler aşağıda verilmiştir [13]. Yumuşak Eşikleme;

$$
\hat{D}_{j, k}= \begin{cases}\operatorname{sgn}\left(D_{j, k}\right) \cdot\left(\left|D_{j, k}\right|-E\right) & \mid D_{j, k} \geq E \\ 0 & \left|D_{j, k}\right|<E\end{cases}
$$

Sert Eşikleme;

$$
\hat{D}_{j, k}= \begin{cases}D_{j, k} & \mid D_{j, k} \geq E \\ 0 & \left|D_{j, k}\right|<E\end{cases}
$$

DD ile birlikte bu eșikleme yöntemlerini kullanan, geleneksel gürültü giderim algoritması aşağıda adımlar halinde verilmiştir [34].

1- Gürültülü sinyale DD uygulanarak $l$ seviyeli ayrışım gerçekleştirilir ve dalgacık katsayıları $\left(D_{j, k}\right)$ hesaplanır.

2- Denklem (8) ile gürültünün varyansı $\left(\sigma^{2}\right)$ hesaplanir.

$$
\sigma^{2}=\frac{\left.m e d\left|D_{j, k}\right|\right)}{0,6745}
$$

Burada med(.) medyanı ifade ederken $D_{j, k}$ ise dalgacık katsayılarını gösterir.

3- Eşik değeri Denklem (9) ile hesaplanır.

$$
E=\sigma^{2} \sqrt{2 \cdot \log (n)}
$$

$E$ eşik değerini, $n$ ise örnek sayısını göstermektedir.

4- $E$ değeri hesaplandıktan sonra uygun eşik seçilerek (sert ya da yumuşak) eşikleme yapılır.

5- Eşikleme işleminde gürültü olarak değerlendirilen dalgacık katsayıları sıfır yapılmışıtır. Sıfır yapılmayan dalgacık katsayıları yeniden birleştirilerek gürülttüden arındırılmış sinyal elde edilir.

\section{5. ÖNERILLEN YÖNTEM (PROPOSED METHOD)}

Önerilen yöntemde, DPD'nin aşağıda tanımlanan bazı parametrelerinin en iyi değerlerini bulabilmek için Genetik Algoritma (GA) kullanılmışıtır. 1975 yılında Holland tarafindan önerilen ve doğal seçim ilkelerine dayanan bir arama ve optimizasyon yöntemi olan GA, Darwin'in canlı organizmalar için kurduğu Evrim teorisi prensibine dayalıdır. GA, daha iyi olan çözümü 
bulabilmek için, çözüm kümesinin oluşturduğu popülasyonu eşzamanlı olarak inceler ve en iyi bireyin hayatta kalmasını sağlar [35]. Önerilen yönteme ait adımlar aşağıda verilmiştir.

Adım 1: Önerilen yöntemin ilk adımını RHE sinyallerinin örneklenmesi oluşturmaktadır.

Adım 2: Yeniden örneklenen orijinal RHE sinyaline gürültü eklenerek gürültülü RHE sinyali elde edilir.

Adım 3: Gürültülü RHE sinyaline DPD uygulanarak $l$ seviyeli ayrışım gerçekleştirilir.

Adım 4: Denklem (8) kullanılarak gürültünün varyans $1\left(\sigma^{2}\right)$ hesaplanır.

Adım 5: Eşik değeri Denklem (9) ile hesaplanır.

Adım 6: Eşikleme fonksiyonu olarak bulanık sfonksiyon kullanılmıştır. $\mathrm{Bu}$ fonksiyona ait eşitlik Denklem (10)' da verilmiştir. Burada " $a$ " ve “ $b$ " sfonksiyon parametrelerdir. Şekil 6 ' $d a a=1$ ve $b=8$ için bir s-fonksiyon çizdirilmiştir.

$$
f\left(D_{j, k} ; a, b\right)= \begin{cases}0 & D_{j, k} \leq a \\ 2\left(\frac{D_{j, k}-a}{b-a}\right)^{2}, & a \leq D_{j, k} \leq \frac{a+b}{2} \\ 1-2\left(\frac{D_{j, k}-b}{b-a}\right)^{2}, & \frac{a+b}{2} \leq D_{j, k} \leq b \\ 1 & D_{j, k} \geq b\end{cases}
$$

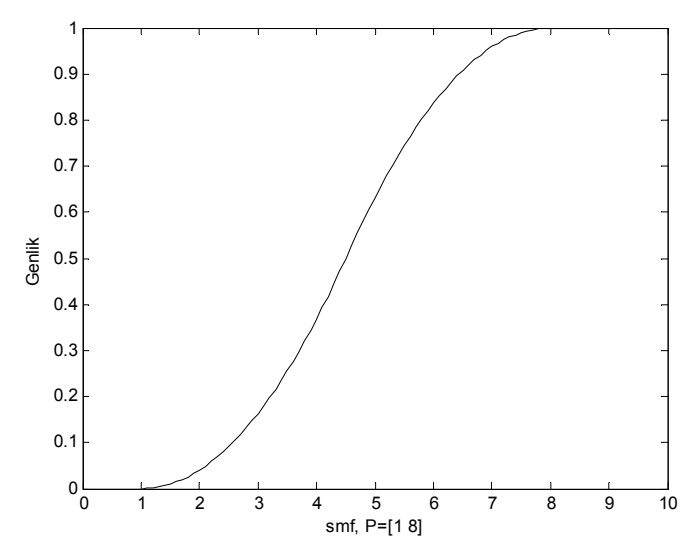

Şekil 6. Bulanık s-fonksiyon eşikleme (Fuzzy s-function threshold)

$\mathrm{Bu}$ yöntemde, GA yapısı kullanılarak dalgacık ailesi türü, entropi türü, dalgacık ayrışım seviyesi değerleri en iyiye yakın olacak şekilde korelasyon katsayısının maksimum olduğu uygunluk fonksiyonu kullanılarak seçilmiştir. Burada, GA'nın her bir bireyi, kullanılan dalgacık türlerini (sırasıyla, Daubechies1, Daubechies2...., Daubechies10, Symlet1, Symlet2, Symlet3, Symlet4, Symlet5, Symlet6, Symlet7, Symlet8, Coiflets1, Coiflets2, Coiflets3, Coiflets4, Coiflets5, Biorthogonal1.1, Biorthogonal1.3, Biorthogonal1.5, Biorthogonal2.2, Biorthogonal2.4, Biorthogonal2.6, Biorthogonal2.8, Biorthogonal3.1, Biorthogonal3.3), entropi türlerini (sırasıyla Shannon, Log enerji, Sure, Norm entropi) ve dalgacık ayrışım seviyelerini (1-8) temsil etmektedir. Şekil 7'de bu şekilde oluşturulmuş bir adet rastgele birey görülmektedir.

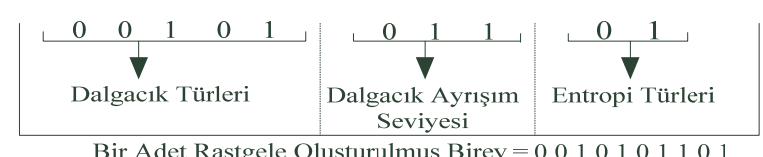

Şekil 7. Rastgele oluşturulmuş birey (Randomly generated individuals)

Yukarıda verilmiş olan GA uygulamasındaki işlemler; 1) Başlangıç Popülasyonunun Oluşturulması: Yukarıda verilen bir adet rastgele oluşturulmuş bireyden 20 adet oluşturularak başlangıç popülasyonu meydana getirilmiştir.

2) Çaprazlama Operatörü: Çaprazlama oranı $\% 60$ seçilerek elde edilen 10 adet iyi bireyin rastgele 6 tanesi kendi aralarında çaprazlama işlemine tabi tutulur. Burada çaprazlama operatörü olarak tek noktalı çaprazlama seçilmiştir.

3) Mutasyon Operatörü: Geriye kalan 4 birey için ise, mutasyon operatörü olarak bit tersleme yöntemi seçilerek buradan yeni 4 adet birey elde edilmiştir.

10 birey ise çaprazlama ve mutasyon işlemine tabi tutulmadan bir sonraki popülasyona aktarılmıştır. Böylelikle yeni popülasyon için toplam 20 adet yeni birey elde edilmiş olur. Yukarıda verilen adımlar tekrarlanarak devam eder. Şekil 4'de $90 \mathrm{~cm}$ mesafede bulunan metal plaka hedefi ve Şekil 5 'de $90 \mathrm{~cm}$ mesafede bulunan küre hedefi için RHE sinyali verilmiştir. $\mathrm{Bu}$ sinyale aşağıda belirtilen oranlarda gürültü eklendikten sonra DPD ve bulanık sfonksiyon eşikleme ile birlikte GA tabanlı yöntem kullanarak RHE sinyallerinin gürültüden arındırılmış grafikleri aşağıda sunulmuştur. Her bir hedef için elde edilen en iyi parametre değerlerine göre grafikler çizdirilip, en iyi parametre değerleriyle birlikte verilmiştir.

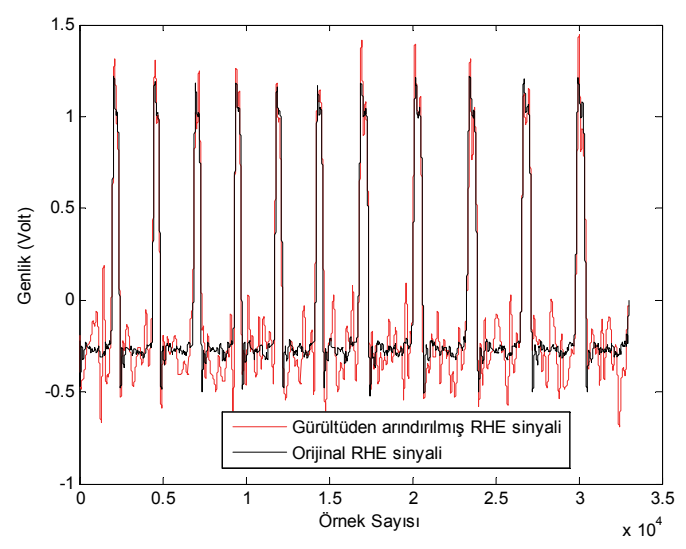

Şekil 8. Metal hedefi için gürültüden arındırılmış RHE sinyali (Denoising RHE signal for the metal target) $(\mathrm{SGO}=-10 \mathrm{~dB}$, sym7,Shannon entropi, 7 seviye) 


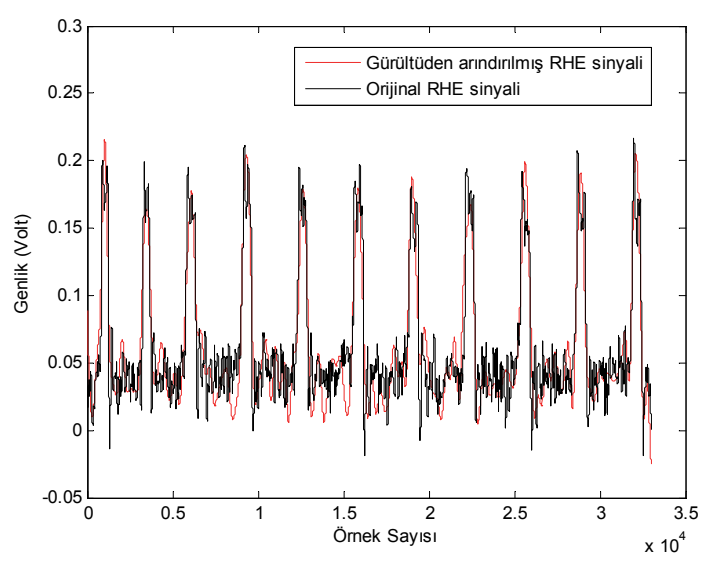

Şekil 9. Küre hedefi için gürültüden arındırılmış RHE sinyali (Denoising RHE signal for the Sphere target) ( $\mathrm{SGO}=-10 \mathrm{~dB}$, sym8,Norm entropi, 8 seviye)

Diğer taraftan, önerilen yöntemin başarımını test etmek için iki farklı değerlendirme kriteri kullanılmıştır. Bunlar sırası ile Ortalama Karesel Hatanın Karekökü (OKHK) ve Korelasyon Katsayısıdır (KK). Bu değerlendirme kriterlerinin matematiksel gösterimleri Denklem (11) ve Denklem (12)'de sırası ile verilmiştir.

$$
\mathrm{O} K H K=\sqrt{\frac{1}{n} \sum_{i=1}^{n}\left(G_{(i)}-T_{(i)}\right)^{2}}
$$

Bu denklemde $G_{(i)}$ orijinal sinyali $T_{(i)}$ ise gürültüden arındırılan sinyali göstermektedir. $n$ ise örnek sayısını ifade etmektedir. KK;

$$
K K=\frac{\sum_{i=1}^{n}\left(G_{i}-\bar{G}\right)\left(T_{i}-\bar{T}\right)}{\sqrt{\sum_{i=1}^{n}\left(G_{i}-\bar{G}\right)^{2} \sum_{i=1}^{n}\left(T_{i}-\bar{T}\right)^{2}}}
$$

\section{6. ÖNERILEN YÖNTEMIN KARŞILAŞTIRILMASI (COMPARISON OF PROPOSED METHOD)}

Bu çalışmada önerilen ve [36], [22] ve [34] nolu kaynaklarda önerilen yöntemlere ait başarım sonuçları karşılaştırmalı olarak aşağıdaki tablolarda verilmiştir.

\begin{tabular}{|c|c|c|c|c|}
\hline $\begin{array}{c}90 \mathrm{~cm} \text { mesafedeki } \\
\text { Metal hedef }(-10 \mathrm{~dB})\end{array}$ & 1.Yöntem [36] & 2.Yöntem [22] & 3.Yöntem [34] & $\begin{array}{l}\text { Önerilen } \\
\text { Yöntem }\end{array}$ \\
\hline $\begin{array}{c}\text { OKHK } \\
\text { KK } \\
\end{array}$ & $\begin{array}{c}0,1584 \\
\% 93,88\end{array}$ & $\begin{array}{c}0,1595 \\
\% 93,94 \\
\end{array}$ & $\begin{array}{c}0,1506 \\
\% 94,61 \\
\end{array}$ & $\begin{array}{c}0,1225 \\
\% 96,46 \\
\end{array}$ \\
\hline $\begin{array}{c}90 \mathrm{~cm} \text { mesafedeki } \\
\text { Metal hedef }(-15 \mathrm{~dB})\end{array}$ & 1.Yöntem [36] & 2.Yöntem [22] & 3.Yöntem [34] & $\begin{array}{l}\text { Önerilen } \\
\text { Yöntem }\end{array}$ \\
\hline $\begin{array}{c}\text { OKHK } \\
\text { KK } \\
\end{array}$ & $\begin{array}{c}0,2272 \\
\% 89,01\end{array}$ & $\begin{array}{c}0,2206 \\
\% 88,35\end{array}$ & $\begin{array}{c}0,1972 \\
\% 90,81\end{array}$ & $\begin{array}{c}\mathbf{0 , 1 8 2 5} \\
\% 92,10\end{array}$ \\
\hline $\begin{array}{c}135 \mathrm{~cm} \text { mesafedeki } \\
\text { Metal hedef }(-10 \mathrm{~dB})\end{array}$ & 1.Yöntem [36] & 2.Yöntem [22] & 3.Yöntem [34] & $\begin{array}{l}\text { Önerilen } \\
\text { Yöntem }\end{array}$ \\
\hline $\begin{array}{c}\text { OKHK } \\
\text { KK } \\
\end{array}$ & $\begin{array}{c}0,1663 \\
\% 92,25 \\
\end{array}$ & $\begin{array}{c}0,1482 \\
\% 93,72 \\
\end{array}$ & $\begin{array}{l}0,1455 \\
\% 93,94 \\
\end{array}$ & $\begin{array}{c}\mathbf{0 , 1 3 8 1} \\
\% 94,74 \\
\end{array}$ \\
\hline $\begin{array}{c}135 \mathrm{~cm} \text { mesafedeki } \\
\text { Metal hedef }(-15 \mathrm{~dB})\end{array}$ & 1.Yöntem [36] & 2.Yöntem [22] & 3.Yöntem [34] & $\begin{array}{l}\text { Önerilen } \\
\text { Yöntem }\end{array}$ \\
\hline $\begin{array}{c}\text { OKHK } \\
\text { KK } \\
\end{array}$ & $\begin{array}{c}0,1976 \\
\% 89,25\end{array}$ & $\begin{array}{c}0,2031 \\
\% 89,07\end{array}$ & $\begin{array}{l}0,1889 \\
\% 89,71 \\
\end{array}$ & $\begin{array}{c}\mathbf{0 , 1 9 6 9} \\
\% 90,69\end{array}$ \\
\hline $\begin{array}{c}180 \mathrm{~cm} \text { mesafedeki } \\
\text { Metal hedef }(-10 \mathrm{~dB})\end{array}$ & 1.Yöntem [36] & 2.Yöntem [22] & 3.Yöntem [34] & $\begin{array}{l}\text { Önerilen } \\
\text { Yöntem }\end{array}$ \\
\hline $\begin{array}{c}\text { OKHK } \\
\text { KK } \\
\end{array}$ & $\begin{array}{c}0,0910 \\
\% 93,74 \\
\end{array}$ & $\begin{array}{c}0,0760 \\
\% 94,53 \\
\end{array}$ & $\begin{array}{c}0,0806 \\
\% 93,56 \\
\end{array}$ & $\begin{array}{c}\mathbf{0 , 0 6 3 8} \\
\% 96,12 \\
\end{array}$ \\
\hline $\begin{array}{c}180 \mathrm{~cm} \text { mesafedeki } \\
\text { Metal hedef }(-15 \mathrm{~dB}) \\
\text { OKHK } \\
\text { KK } \\
\end{array}$ & $\begin{array}{c}\text { 1.Yöntem [36] } \\
0,1145 \\
\% 88,27 \\
\end{array}$ & $\begin{array}{c}\text { 2.Yöntem [22] } \\
0,1115 \\
\% 88,01 \\
\end{array}$ & $\begin{array}{c}\text { 3.Yöntem [34] } \\
0,1045 \\
\% 89,59 \\
\end{array}$ & $\begin{array}{c}\text { Önerilen } \\
\text { Yöntem } \\
\mathbf{0 , 0 9 9 5} \\
\% \mathbf{9 0 , 6 6} \\
\end{array}$ \\
\hline
\end{tabular}

Tablo 2. Metal hedefi için incelenen yöntemlerin karşılaştırılması (Comparison of the methods for the metal target) 
Tablo 3. Küre hedefi için incelenen yöntemlerin karşılaştırılması (Comparison of the investigated methods for the sphere target)

\begin{tabular}{|c|c|c|c|c|}
\hline $\begin{array}{c}90 \mathrm{~cm} \text { mesafedeki } \\
\text { Küre hedefi }(-10 \\
\mathrm{dB})\end{array}$ & 1.Yöntem [36] & 2.Yöntem [22] & 3.Yöntem [34] & $\begin{array}{l}\text { Önerilen } \\
\text { Yöntem }\end{array}$ \\
\hline ОКНК & 0,0273 & 0,0240 & 0,0230 & $\mathbf{0 , 0 2 3 2}$ \\
\hline KK & $\% 88,05$ & $\% 87,84$ & $\% 87,90$ & $\% \mathbf{8 9 , 0 7}$ \\
\hline $\begin{array}{c}90 \mathrm{~cm} \text { mesafedeki } \\
\text { Küre hedefi }(-15 \\
\mathrm{dB})\end{array}$ & 1.Yöntem [36] & 2.Yöntem [22] & 3.Yöntem [34] & $\begin{array}{l}\text { Önerilen } \\
\text { Yöntem }\end{array}$ \\
\hline $\begin{array}{c}\text { OKHK } \\
\text { KK } \\
\end{array}$ & $\begin{array}{c}0,0378 \\
\% 74,16\end{array}$ & $\begin{array}{c}0,0364 \\
\% 75,03\end{array}$ & $\begin{array}{c}0,0345 \\
\% 79,63\end{array}$ & $\begin{array}{c}\mathbf{0 , 0 2 9 2} \\
\% \mathbf{8 4 , 6 1}\end{array}$ \\
\hline $\begin{array}{c}135 \mathrm{~cm} \text { mesafedeki } \\
\text { Küre hedefi }(-10 \\
\text { dB })\end{array}$ & 1.Yöntem [36] & 2.Yöntem [22] & 3.Yöntem [34] & $\begin{array}{l}\text { Önerilen } \\
\text { Yöntem }\end{array}$ \\
\hline $\begin{array}{c}\text { OKHK } \\
\text { KK } \\
\end{array}$ & $\begin{array}{c}0,0262 \\
\% 77,11 \\
\end{array}$ & $\begin{array}{c}0,0253 \\
\% 77,67 \\
\end{array}$ & $\begin{array}{c}0,0212 \\
\% 83,56\end{array}$ & $\begin{array}{c}\mathbf{0 , 0 2 1 4} \\
\% \mathbf{8 5 , 1 0}\end{array}$ \\
\hline $\begin{array}{c}135 \mathrm{~cm} \text { mesafedeki } \\
\text { Küre hedefi }(-15 \\
\text { dB) }\end{array}$ & 1.Yöntem [36] & 2.Yöntem [22] & 3.Yöntem [34] & $\begin{array}{l}\text { Önerilen } \\
\text { Yöntem }\end{array}$ \\
\hline $\begin{array}{c}\text { OKHK } \\
\text { KK } \\
\end{array}$ & $\begin{array}{c}0,0332 \\
\% 65,86 \\
\end{array}$ & $\begin{array}{c}0,0313 \\
\% 68,59 \\
\end{array}$ & $\begin{array}{c}0,0306 \\
\% 70,44 \\
\end{array}$ & $\begin{array}{c}\mathbf{0 , 0 3 1 7} \\
\% 72,71 \\
\end{array}$ \\
\hline $\begin{array}{c}180 \mathrm{~cm} \text { mesafedeki } \\
\text { Küre hedefi }(-10 \\
\mathrm{dB})\end{array}$ & 1.Yöntem [36] & 2.Yöntem [22] & 3.Yöntem [34] & $\begin{array}{l}\text { Önerilen } \\
\text { Yöntem }\end{array}$ \\
\hline $\begin{array}{c}\text { OKHK } \\
\text { KK }\end{array}$ & $\begin{array}{c}0,0192 \\
\% 58,77 \\
\end{array}$ & $\begin{array}{c}0,0174 \\
\% 66,15 \\
\end{array}$ & $\begin{array}{c}0,0168 \\
\% 67,48 \\
\end{array}$ & $\begin{array}{c}\mathbf{0 , 0 1 6 8} \\
\% 68,48 \\
\end{array}$ \\
\hline $\begin{array}{c}180 \mathrm{~cm} \text { mesafedeki } \\
\text { Küre hedefi }(-15 \\
\mathrm{dB})\end{array}$ & 1.Yöntem [36] & 2.Yöntem [22] & 3.Yöntem [34] & $\begin{array}{l}\text { Önerilen } \\
\text { Yöntem }\end{array}$ \\
\hline $\begin{array}{c}\text { OKHK } \\
\text { KK }\end{array}$ & $\begin{array}{c}0,0263 \\
\% 51,38\end{array}$ & $\begin{array}{c}0,0269 \\
\% 50,18\end{array}$ & $\begin{array}{c}0,0276 \\
\% 52,74\end{array}$ & $\begin{array}{c}\mathbf{0 , 0 2 3 9} \\
\% \mathbf{5 6 , 2 5}\end{array}$ \\
\hline
\end{tabular}

Tablo 2 ve Tablo 3'de her iki hedefe ait $-10 \mathrm{~dB}$ ve -15 $\mathrm{dB}$ gürültü oranlarında başarım sonuçları yer almaktadır.

İncelenen yöntemlerin ilkini DPD ve Entropi tabanlı bir yaklaşım oluşturmaktadır [36]. Bu yöntemde, Daubechies3 dalgacık ailesi, Sure entropi ve ayrışım için 8 seviye seçilmiştir. İncelenen yöntemin etkinliği, gerçek RHE sinyalleri üzerinde gerçekleştirilen uygulamalar ile gösterilmiştir.

İncelenen ikinci yöntem, Dalgacık Dönüşümü ve Seviye Bağımlı Eşikleme ile zayıf RHE sinyallerinde gürültü arındırma uygulamasıdır [22]. Bu yöntemde, ilk yöntemde olduğu gibi, Daubechies 3 dalgacık ailesi ve ayrışım için 8 seviye seçilmiştir. Seçilen bu parametreler deneysel çalışmalar sonucunda bulunan en iyi değerlerdir. Karşılaştırmanın doğru yapılabilmesi için ilk üç yöntemde de aynı dalgacık parametreleri kullanılmıştır.
İncelenen üçüncü yöntem, Dalgacık Paket Dönüşümü ve Bulanık s-fonksiyon Eşikleme ile zayıf RHE sinyallerinde gürültü arındırma uygulamasıdır [34]. $\mathrm{Bu}$ yöntemde, ilk iki yöntemde olduğu gibi dalgacık ailesi olarak Daubechies3, Sure entropi ve 8 seviye seçilmiştir.

Önerilen yöntemde, GA ile en iyi dalgacık ailesi, entropi türü ve ayrışım seviyesi seçilebilmiştir. Tablo 2'de, metal hedefi $90 \mathrm{~cm}$ mesafede ve SGO oranı -10 $\mathrm{dB}$ değerinde iken, önerilen yöntem ile KK değeri \%96,46 olmaktadır. Bu değer, diğer yöntemlerden elde edilen sonuçlardan oldukça iyidir. Benzer şekilde, küre hedefi için $90 \mathrm{~cm}$ ve $\mathrm{SGO}=-10 \mathrm{~dB}$ değerinde $\mathrm{KK}=\% 89,07$ olmaktadır. Tablo 2 ve 3 incelendiğinde, farklı mesafeler ve SGO oranları için önerilen yöntemden elde edilen sonuçların çok daha iyi olduğu görülebilmektedir. 


\section{SONUÇ (CONCLUSION)}

Bu çalışmada, gürültüye maruz kalmış zayıf RHE sinyallerini gürültüden arındırabilmek için bir algoritma önerilmiştir. RHE sinyalleri 9620/21 Model Lab-Volt radar deney seti kullanılarak elde edilmiştir. Laboratuar ortamında farklı hedefler için elde edilen RHE sinyallerine, farklı SGO $(-10,-15 \mathrm{~dB})$ oranlarında beyaz gürültü eklenerek önerilen yöntemin başarımı test edilmiştir. Elde edilen sonuçlar daha sonra [36], [22] ve [34]'de önerilen yöntemler ile karşılaştırılmıştır. Karşılaştırma yapılırken başarım kriteri olarak OKHK ve KK kullanılmış ve sonuçlar tablo şeklinde verilmiştir. $\mathrm{Bu}$ çalışmada verilen her iki hedef ve hedef mesafesi için önerilen yöntemin başarım sonuçlarının diğer yöntemlerden çok daha iyi olduğu tablolar karşılaştırıldığında rahatlıkla görülebilir. Bunun nedeni her gürültü seviyesi için GA tarafindan elde edilen dalgacık parametre değerleridir. $\mathrm{Bu}$ algoritma ile gürültülü radar sinyallerinin gürültüden arındırılması daha etkili olmaktadır.

\section{KAYNAKLAR (REFERENCES)}

1. Yang, B.J. ve Li, Y., "Introduction of chaotic oscillator detection", Beijing: Publish House of Electronics Industry, 2004.

2. Couch, I., Digital and Analog Communication Systems, Maxwell MacMillan, New York, A.B.D., 1990.

3. Cunningham, I. A., ve Shaw, R., "Noise in imaging systems and humaan vision: signal-tonoise optimization of medical imaging systems", Journal of the Optical Society of America, A16 (3), s.621-632. 1999.

4. Chen, W., Meng C., Wang C. ve Zhang, Z., "Summary on weak signal detection methods based on chaos theory", The Ninth International Conference on Electronic Measurement and Instruments, 978-1-42443864-8/09, IEEE, 2009.

5. Wang, G., ve diğ.., "Application of chaos oscillator in detection of signal under the background of strong noise", Beijing: Chinese Journal of Scientific Instrument, 18(2), 209212. 1997.

6. Ehara, N., Sasese, I. ve Mori, S., "Weak radar signal detection based on wavelet transform", IEEE, 0-7803-1775-0/94, 1994.

7. Ahern, J., Delisle, G. Y. ve diğ., Radar, LabVolt Ltd., vol. 1, Canada. 1989.

8. Ahern, J., Delisle, G. Y. ve diğ., Radar, LabVolt Ltd., vol. 2, Canada. 1990.

9. Aly, O.A.M. ve Omar A.S., "Detection and localization of RF radar pulses in noise environments using wavelet packet transform and higher order statistics", Progress in Electromagnetics Research, PIER 58, 301-317, 2006.
10. Wei, C. ve Zhu, W., "Weak signal denoising method based on accumulation in frequency domain and wavelet transform", Third International Symposium on Information Processing, IEEE, 2010.

11. Chongsheng L., "Study of weak signal detection based on second FFT and chaotic oscillator", Nature and Science, 3(2), 2005.

12. Khairnar, D.G., Merchant, S.N., Desai, U.B., "Radar signal detection in non-gaussian noise using RBF neural network", Journal of Computers, Vol.3, No.1. 2008.

13. To, A.C., Moore, J.R., Glaser, S.D., "Wavelet denoising techniques with applications to experimental geophysical data”, Signal Processing, 89, 144-160, 2009.

14. Yang, R., Ren, M., "Wavelet denoising using principal component analysis", Expert systems with Applications, 38, 1073-1076, 2011.

15. Sharma, L.N., Dandapat S. ve Mahanta A., "ECG signal denoising using higher order statistics in wavelet subbands", Biomedical Signal Processing and Control, 5, 214-222. 2010.

16. Bingo W.K, L., Charlotte H., Hak-Keung L., Thomas P.L, W., Albert, Y., Peter, S., "Fuzzy rule based multiwavelet ECG signal denoising", IEEE International Conference on Fuzzy Systems, 2008.

17. Geetha, G. ve Geethalakshmi S.N., "EEG Denoising using sure thresholding based on wavelet transforms", International Journal of Computer Applications, 0975-8887, Vol.24, No.6, 2011.

18. Talbi, M., Salhi, L., Barkouti, W. ve Cherif A., "Speech enhancement with bionic wavelet transform and recurrent neural network", 5th International Conference: Sciences of Electronic, Technologies of Information and Telecommunications, March. 2009.

19. Kumar, B.M. ve Lavanya, R.V., "Signal denoising with soft threshold by using chui-lian multiwavelet", International Journal of Electronics and Communication Technology, Vol.2, Issue 1, March, 2011.

20. Liu, L. ve Jiang J., "Using stationary wavelet transformation for signal denoising”, Eighth International Conference on Fuzzy Systems and Knowledge Discovery, IEEE, 2011.

21. Song, S., Qi, Y.Y. ve Qiao, J.F., "Research on de-noising of pulse signal based on fuzzy threshold in wavelet packet domain", Proceedings of the 2007 International Conference on Wavelet Analysis and Pattern Recognition, Beijing, China, 2-4 Nov., 2007.

22. Zhang, Q., Rossel, R.A. ve Choi, P., "Denoising of gamma-ray signals by interval-dependent thresholds of wavelet analysis", Measurement Science and Technology, 17, 731-735, 2006. 
23. Liu, F., Ruan, X.E., "Wavelet-based diffusion approaches for signal denoising", Signal Processing, 87, 1138-1146, 2007.

24. Xiang, D.Li., Lai-Bin, Z. ve Zhao-Hui, W., "Denoising of diesel vibration signal using wavelet packet and singular value decomposition", Front.Mech.Eng.China, 4:443-447, 2006.

25. Alfaouri, M. ve Daqrouq K., "ECG signal denoising by wavelet transform thresholding", American Journal of Applied Sciences, 5(3):276-281. 2008.

26. Ravier, P. ve Amblard, P., "Wavelet packets and de-noising based on higher order statistics for transient detection", Signal Processing, 81, 1909-1926, 2001.

27. Medina, C.A., Alcaim, A. ve Apolinario J.A., "Wavelet denoising of speech using neural networks for threshold selection", Electronics Letters $1^{\text {th }}$, Vol.39, No.25, December, 2003.

28. Chen, G.Y. ve Bui, T.D., "Multiwavelets denoising using neighboring coefficients", IEEE Signal Processing Letters, Vol.10, No.7, July, 2003.

29. Arı, N., Özen, Ş. ve Çolak, Ö.H., Dalgacık Teorisi, Palme Yayıncılık, Ankara, 2008.

30. Fliege, N.J., Multirate digital signal processing (Multirate systems-filter bankswavelets, John Wiley \& Sons, Chichester, 251 p. 1996.
31. Misiti, M., Misiti, Y., Oppenheim, G., Poggi, J.M., Wavelet toolbox users guide, copyright by the MathWorks, Inc., 1996-1997.

32. Üstündağ, M., Zayıf radar sinyallerinin genetik algoritmalar kullanılarak gürültüden arındırılması, Doktora Tezi, Firat Üniversitesi, Fen Bilimleri Enstitüsü, 2012.

33. Avcı, E., Akıllı radar ile hedef tanıma sistemi, Doktora Tezi, Frrat Üniversitesi, Fen Bilimleri Enstitüsü 2005.

34. Üstündağ, M., Gökbulut, M., Şengür, A. ve Ata, F., "Denoising of weak ECG signals by using wavelet analysis and fuzzy thresholding", Springer, 1:135-140, 2012.

35. Demirel, N., Gökçen, H., Akçayol, M.A. ve Demirel, E., "Çok aşamalı bütünleşik lojistik ağı optimizasyonu probleminin melez genetik algoritma ile çözümü”, Journal of the Faculty of Engineering and Architecture of Gazi University, Cilt 26, No 4, 929-936, 2011.

36. Üstündağ, M., Şengür, A., Gökbulut, M. ve Ata, F., "Zayıf radar sinyallerinde gürültü gidermek için dalgacık paket dönüşümü ve entropi tabanlı bir yöntem", Fırat Üniversitesi Mühendislik Bilimleri Dergisi, Cilt 24, Say1 2, 139-147, 2012 
